\title{
Short communication: Genetic relationships between the Holstein cow populations of three European dairy countries
}

\author{
R. Mrode, ${ }^{* 1}$ J. F. Kearney, $†$ S. Biffani,ł M. Coffey, ${ }^{*}$ and F. Canavesił \\ *Scottish Agricultural College, Sir Stephen Watson Building, Penicuik, EH26, OPH, United Kingdom \\ †rish Cattle Breeding Federation, High Field House, Bandon, Co. Cork, Ireland \\ $\ddagger$ Associazione Nazionale Allevatori Frisona Italiana (ANAFI), Italian Holstein Breeders Association 292- Cremona, 26100 Italy
}

\begin{abstract}
The degree of relatedness was studied in 3 dairy cow populations from Great Britain (GBR), Italy (ITA), and Ireland (IRL) by using cows born from 2003 to 2006. Effective population size, inbreeding coefficient $(F)$, and average relationship in the top and bottom 4,000 cows ranked on a profit index value (PIV) or milk yield evaluations were studied. Average inbreeding was approximately $2 \%$ in GBR and ITA, was $1 \%$ in IRL, but was slightly more than $2 \%$ when the joint pedigree was used. The average $F$ for the joint population was 10 to $15 \%$ higher than estimates averaged across the 3 populations, reflecting the increased completeness of pedigree information in the joint pedigree. Effective population size in the joint pedigree was approximately $12 \%$ lower than estimates within the individual countries. The average genetic relationships for the top 4,000 PIV cows were not markedly different from those based on milk evaluation in GBR and ITA, but were approximately $2 \%$ lower in IRL. This was due to the use of an index with less weight on production traits in IRL compared with GBR and ITA. However, selection of the top 4,000 cows on PIV reduced the degree of relatedness across the 3 countries. The use of common sires accounted for most of the relatedness across the 3 countries, more than did the use of related sires or common foreign dams.
\end{abstract}

Key word: genetic relationship, Holstein cow, inbreeding

In the last $30 \mathrm{yr}$, there has been a steady increase in the importation of foreign genotypes, mainly from North America, to replace commercial dairy Black and White cattle populations in many countries. This "holsteinization" process has been accelerated by improvements in reproductive technology beginning in the 1980s and the availability of international evaluations from Interbull

Received November 26, 2008.

Accepted July 15, 2009.

${ }^{1}$ Corresponding author: raphael.mrode@sac.ac.uk in the last $15 \mathrm{yr}$ (Wickham and Banos, 1998). This has resulted in Holstein bulls with similar parentage being tested simultaneously in several countries and has also resulted in the heavy use of top-ranking bulls in cow populations in several countries.

A major concern about the emergence of the global breeding structure of the Holstein breed has been the apparent reduction in effective population size $(\mathbf{N e})$ and loss of genetic diversity. Wickham and Banos (1998) reported that the average genetic relationship of sires of sons born in 1990 was 6 times greater than that of sons born in 1970. The ratio of Ne to actual population size was approximately 0.22 for sires born in 1990, compared with 0.98 in 1975. Mrode et al. (1998) indicated that, for bulls with progeny test results, the percentage that were the sons of the 5 most used sires increased from approximately $30 \%$ in 1981 to approximately 50 to $70 \%$ in 1991 in many countries. Fikse and Philipsson (2007) indicated, from an analysis of Interbull pedigree data, that half of all progeny-tested bulls between 1983 and 1985 in the Holstein breed were sired by one bull sire. Weigel et al. (2000) examined the average genetic relationship among a sample of 1,000 Holstein cows with yield records in 15 countries. There were large variations in the estimates of average relationships, with very low values between countries such as Estonia and Finland, Germany and Finland, and Germany and Israel, where there is little or no direct international trade in semen and embryos. In contrast, average relationships were higher between countries such as Canada and Australia, Ireland and the Netherlands, and South Africa and the United States. However, the genetic relationships among top cows ranked on the basis of genetic evaluations for milk or national selection indexes in dairy cattle populations from different countries have not been reported. The use of a unique profit index with broader breeding goals in each country for the selection of bulls for breeding purposes should result in a wider range of bulls being selected across countries and hence a reduction in the rate of decline in Ne. This study therefore examines the genetic relationships among top cows based on an index 
Table 1. The number $(\mathrm{N})$ of cows born in each country, percentage with both parents known (Both), and average number of equivalent generations $(\text { Gen })^{1}$ in the year of birth

\begin{tabular}{|c|c|c|c|c|c|c|c|c|c|}
\hline \multirow[b]{2}{*}{ Year } & \multicolumn{3}{|c|}{ Great Britain } & \multicolumn{3}{|c|}{ Italy } & \multicolumn{3}{|c|}{ Ireland } \\
\hline & $\mathrm{N}$ & Both & Gen & $\mathrm{N}$ & Both & Gen & $\mathrm{N}$ & Both & Gen \\
\hline 2004 & 301,873 & 99 & $5.08(5.33)$ & 314,657 & 94 & $5.28(5.61)$ & 62,429 & 97 & $4.19(4.98)$ \\
\hline 2005 & 277,957 & 99 & $5.21(5.46)$ & 309,744 & 95 & $5.39(5.74)$ & 42,173 & 98 & $3.75(5.42)$ \\
\hline 2006 & 84,749 & 99 & $5.28(5.53)$ & 297,532 & 95 & $5.55(5.89)$ & 115,760 & 99 & $4.57(5.41)$ \\
\hline
\end{tabular}

${ }^{1}$ Numbers in brackets are equivalent generations estimated from the joint pedigree.

or on milk evaluations for cows born from 2003 to 2006 in 3 European dairy countries, Great Britain (GBR), Italy (ITA), and Ireland (IRL). In addition, the average levels of inbreeding and Ne within and across the 3 populations over time were studied.

For cows born from 2003 to 2006, national genetic evaluations for milk yield and the profit index value (PIV) used in each country and the full pedigree of cows of up to 5 generations were obtained from the Edinburgh Genetic Evaluation Services in GBR; ANAFI, the Italian Holstein Breeders Association in ITA; and the Irish Cattle Breeding Federation in IRL. Some cows born in 2005 and 2006 were too young to be evaluated, so a pedigree index was calculated for these cows. The higher number of cows in 2006 for IRL (Table 1) was due to the inclusion of all females in the database without any requirement that they should be milk recorded.

The composition of the national profit index used in the 3 countries is summarized in Table 2, with GBR, ITA, and IRL placing a relative emphasis, on the basis of economic weights of 77,59 , and $42 \%$, respectively, on production traits. The full descriptions of the national profit indexes have been reported by Stott et al. (2005) for GBR, Biffani et al. (2002) for ITA, and the Irish Cattle Breeding Federation (2008) for IRL. Inbreeding coefficients $(F)$ were computed for each population and for a joint pedigree from the 3 populations. The number of equivalent generations $(t)$ was calculated for all cows in the pedigree as the sum over all known ancestors of the term $(0.5)^{n}$, where $n$ is the number of generations between ancestor $i$ and the cow (Maignel et al., 1996). Effective population size was calculated for various populations subsets as $1 /(2 b)$, where $b$ is the regression of $F$ on $t$ for the relevant population subset, and it roughly estimates inbreeding rate.

The computation of average genetic relationship (AGREL) for cows within year of birth was not feasible because of the large number of cows. Therefore, AGREL was computed for only the top and bottom 4,000 cows ranked on PIV or milk evaluations both within and across countries. All computations of inbreeding and AGREL were carried out using RelaX2 software (Stranden and Vuori, 2006). To measure the degree of relatedness among the 3 populations resulting from completeness of pedigree and the use of common sires and dams, estimates of $F$ and AGREL from the joint pedigree were compared with values averaged from estimates for the individual countries (referred to as "expected"). For instance, consider the AGREL among the top 4,000 cows calculated initially within each country. Then, AGREL-expected for the 3 populations equals

$$
\frac{1}{n} \sum_{i=1}^{3} a_{i}
$$

where $a_{\mathrm{i}}$ is the sum of nonzero elements of the relationship matrix among the top 4,000 computed within the ith population, and $n=\{0.5[m(m+1)]-m\}$, with $m$ $=12,000$ (the sum of the top 4,000 in each country).

Table 2. Summary of the national profit index in the 3 countries in terms of percentage emphasis based on economic weights on various traits

\begin{tabular}{lccc}
\hline Trait & Great Britain & Italy & Ireland \\
\hline Production (milk, fat, and protein) & 77 & 59 & 42 \\
Health (lameness, udder, mastitis, or SCC) & 6 & 23 & 4 \\
Survival & 17 & 8 & $34^{1}$ \\
Functional legs and feet & & 6 & \\
Type traits & & 4 & 11 \\
Calving traits & & 9 \\
Beef traits & & & 9 \\
\hline
\end{tabular}

${ }^{1}$ Survival and fertility subindex. 
Table 3. Average percentage inbreeding coefficient in each of 3 populations and in the joint pedigree by year ${ }^{1}$

\begin{tabular}{ccccccc}
\hline Year & Great Britain & Italy & Ireland & ALL-E & ALL-O & $\%$ P \\
\hline 2003 & 1.85 & 2.13 & 1.04 & 1.89 & 2.06 & 9.0 \\
2004 & 1.96 & 2.15 & 1.03 & 1.96 & 2.17 & 10.7 \\
2005 & 2.09 & 2.21 & 0.07 & 2.06 & 2.29 & 11.2 \\
2006 & 2.15 & 2.32 & 1.16 & 2.02 & 2.32 & 14.9 \\
\hline
\end{tabular}

${ }^{1}$ ALL-E $=$ inbreeding averaged across the 3 populations (expected); ALL-O = observed average inbreeding coefficient in the 3 populations; $\% \mathrm{P}=$ percentage increase in observed compared with expected.

The subtraction of $m$ in the equation is to account for the fact that the diagonal elements of the animals are not included in the calculation. The deviation of the actual AGREL calculated from the joint pedigree from AGREL-expected indicates the degree of relatedness among the 3 populations resulting from the completeness of pedigree and the use of common sires and dams. In the case of $F$, this difference will reflect mostly completeness of pedigree information in the joint pedigree.

The relationship among the 3 populations could be due to the use of the same or related sires and the progeny of the same or related sires. In addition, the importation of embryos suggests that similar foreign cows are used as bull dams across the 3 countries. There were 528 and 384 common sires and dams in the 3 countries, respectively, for cows born from 2003 to 2006. There were 367,280 , and 147 common sires used in GBR and ITA, GBR and IRL, and ITA and IRL. The degree of relatedness attributable to common sires was estimated by recoding these bulls and their pedigrees with a unique identity within each country in the joint pedigree and comparing estimates of AGREL with those from the analysis with a full pedigree. In addition, the degree of relatedness among the common sires and related sires used in the different countries was examined by estimating the AGREL among all sires.

The number of cows with both parents known varied from 94 to $99 \%$ and the average $t$ estimated for each population from the joint pedigree was approximately 5 , except for IRL, for which it was approximately 4 in the years 2003 to 2005 (Table 1). Similarly, Maignel et al. (1996) reported $t$ values of 4.75, 5.02, and 4.19 for the Holstein, Normande, and Montbeliarde breeds, respectively, in France. The estimates of $t$ from the joint pedigree were higher than estimates within the individual countries, indicating that the 3 countries could further improve the depth of pedigree by exchanging parentage data on cows.

The average $F$ in each year was approximately $2 \%$ for GBR and ITA but was lower in IRL, at approximately 1\% (Table 3). Sorensen et al. (2005) reported higher average inbreeding values of 3.9 and 3.4 for Holstein and Jersey calves born in 2003 but a similar estimate of 1.45 for Danish Red calves. However, they reported a high degree of pedigree completeness in all 3 populations. The average $F$ from the joint pedigree was generally higher than observed within each country and was 10 to $15 \%$ higher compared with the expected value averaged from the individual 3 populations. The majority of this increase (approximately $80 \%$ ) was due to the completeness of pedigree for common sires used across the 3 populations. Fikse et al. (2006) reported that across-country selection of bulls was highest in the Holstein compared with other dairy breeds when data from 27 countries were considered. They indicated that on average 120 Holstein sires had daughters in both countries for any given country pair and 2 countries shared on average 77 Holstein bull sires.

The Ne calculated within each country was approximately 100 in each year for GBR and ITA but was higher for IRL, from 120 (2003) to 126 (2004). These values are higher than the effective population size of 46 reported for the Holstein in France (Maignel et al., 1996) but are similar to the value of 125 for the Montbeliarde breed. However, Ne from the joint pedigree was 97 in 2003 and declined to 87 in 2006. The lower $\mathrm{Ne}$ in the joint pedigree reflects the increase in inbreeding levels and the use of common sires in the 3 populations. This is consistent with the observation of Wickham and Banos (1998) that the effective population size of bulls born in 1990 was only $22 \%$ of the actual population, compared with $98 \%$ for the bulls born in 1975 . However, more recent studies (Mark et al. 2002; Fikse and Philipsson, 2007) seem to indicate that the extreme use of Holstein bull sires has been tempered for bulls born after 1987, with estimated Ne increasing from 55 to 449 for bulls born in 1995 and 1999, respectively.

The average genetic relationship among the top 4,000 cows (Table 4) was approximately $9 \%$ for ITA across the 4 yr, increased from 6 to $10 \%$ in GBR, and increased from 3 to $12 \%$ for IRL. The high AGREL in 2006 for IRL and GBR is mainly a result of ranking the cows on pedigree indexes. Across the 3 populations, the AGREL varied from 5 to $7 \%$ and were lower than within each country. However, these values were approximately 113 to $145 \%$ higher than the values averaged from esti- 
Table 4. Percentage average genetic relationship among the top and bottom 4,000 index cows within each country and among the top and bottom 12,000 cows across 3 countries in each year of birth ${ }^{1}$

\begin{tabular}{|c|c|c|c|c|c|c|c|c|c|c|c|c|}
\hline \multirow[b]{2}{*}{ Year } & \multicolumn{2}{|c|}{ Great Britain } & \multicolumn{2}{|c|}{ Italy } & \multicolumn{2}{|c|}{ Ireland } & \multicolumn{2}{|c|}{ ALL-E } & \multicolumn{2}{|c|}{ ALL-O } & \multicolumn{2}{|c|}{$\% \mathrm{P}$} \\
\hline & Top & Bottom & Top & Bottom & Top & Bottom & Top & Bottom & Top & Bottom & Top & Bottom \\
\hline 2004 & 5.66 & 1.99 & 8.29 & 1.39 & 2.77 & 4.38 & 1.86 & 0.92 & 4.55 & 2.51 & 145 & 172 \\
\hline 2005 & 10.4 & 2.22 & 8.81 & 0.69 & 2.65 & 1.66 & 2.42 & 0.51 & 5.31 & 1.08 & 119 & 112 \\
\hline 2006 & 8.31 & 2.18 & 8.74 & 0.59 & 10.71 & 4.83 & 3.08 & 0.84 & 6.57 & 1.94 & 113 & 131 \\
\hline
\end{tabular}

${ }^{1} \mathrm{ALL}-\mathrm{E}=$ average relationship averaged across the 3 populations (expected); ALL-O = observed average relationship in 3 populations; \% $\mathrm{P}=$ percentage increase in observed compared with expected.

mates within the individual countries. Analysis of the joint pedigree with common sires and their pedigrees uniquely coded within each country indicated that the use of common sires accounted for approximately $84 \%$ of this increase. As expected, AGREL for the bottom 4,000 cows were very low in GBR and ITA, but in IRL this was the case only in the last 2 yr (2005 to 2006). In IRL, the average relationship was higher in the bottom 4,000 cows in 2003 and 2004 compared with the top cows. A possible explanation is that the IRL PIV places only $42 \%$ emphasis on production (Table 2); therefore, the top cows are selected from more unrelated families. For instance, the top 4,000 PIV cows in IRL were the progeny of 350 sires with an average relationship of $2.14 \%$, compared with the bottom 4,000 PIV cows sired by 764 sires with an average relationship of $5.86 \%$. The reversal of this trend in the last 2 yr in IRL was due to the ranking of animals based on pedigree index; therefore, the daughters of fewer widely used sires dominated this top cow list, hence the higher average relationship among the top cows. For example, 198 sires were represented in the top 4,000 cow list for IRL in 2005 compared with 1,035 sires in the bottom 4,000 cows.

Considering the first $2 \mathrm{yr}$ in which cows had observations, the average genetic relationship for the top 4,000 cows on milk evaluations was approximately 1 to $2 \%$ lower compared with the top index cows for GBR and ITA (Table 5), but was approximately $2 \%$ higher for IRL. The high weight on protein in the PIV for
GBR and ITA and a negative or zero weight on milk may have resulted in slightly more related cows being selected based on the index. The opposite is true for IRL because of the much lower weight on production traits. Interestingly, the AGREL was approximately $20 \%$ higher in the top 12,000 cows ranked on milk, compared with the index across the 3 populations for the first $2 \mathrm{yr}$ not based on pedigree index. Thus, selection based on the index has resulted in a reduction in relatedness across the 3 countries. This could be because the genetic correlation for the 3 countries might be higher for milk evaluations than for PIV. The trend is less clear in the last $2 \mathrm{yr}$, when pedigree indexes were used in the selection of cows.

As indicated, the use of the same sires and related sires accounted for most of the relatedness between the 3 populations. Table 6 summarizes the number of bulls that sired cows in each country over the $4 \mathrm{yr}$. If sires with at least 20 daughters were considered, then approximately $750,1,129$, and 269 bulls in GBR, ITA, and IRL, respectively, accounted for $80 \%$ of the daughters born from 2003 to 2006 . Of these bulls, $44 \%$ of those used in IRL and $16 \%$ used in ITA were common to those in GBR. Mrode et al. (1998) reported that the percentage of the top 5 sires in common use in GBR, ITA, France, and the Netherlands increased by approximately $40 \%$ when the periods 1981 to 1985 and 1988 to 1992 were compared. Fikse et al. (2006) reported that the proportion of foreign proven bulls used to breed cows for the commercial population was

Table 5. Percentage average genetic relationship among the top and bottom 4,000 cows ranked on milk evaluations within each country and among the top and bottom 12,000 cows across 3 countries in each year of birth ${ }^{1}$

\begin{tabular}{|c|c|c|c|c|c|c|c|c|c|c|c|c|}
\hline \multirow[b]{2}{*}{ Year } & \multicolumn{2}{|c|}{ Great Britain } & \multicolumn{2}{|c|}{ Italy } & \multicolumn{2}{|c|}{ Ireland } & \multicolumn{2}{|c|}{ ALL-E } & \multicolumn{2}{|c|}{ ALL-O } & \multicolumn{2}{|c|}{$\% \mathrm{P}$} \\
\hline & Top & Bottom & Top & Bottom & Top & Bottom & Top & Bottom & Top & Bottom & Top & Bottom \\
\hline 2004 & 5.46 & 2.25 & 6.49 & 1.44 & 4.20 & 1.17 & 1.79 & 0.54 & 5.59 & 1.28 & 212 & 137 \\
\hline 2005 & 6.32 & 1.65 & 7.23 & 0.81 & 2.77 & 1.13 & 1.81 & 0.40 & 5.19 & 0.73 & 187 & 83 \\
\hline 2006 & 6.27 & 1.75 & 7.93 & 0.91 & 5.05 & 3.28 & 2.14 & 0.66 & 6.48 & 1.44 & 203 & 118 \\
\hline
\end{tabular}

${ }^{1} \mathrm{ALL}-\mathrm{E}=$ average relationship averaged across the 3 populations (expected); ALL-O = observed average relationship in 3 populations; $\% \mathrm{P}=$ percentage increase in observed compared with expected. 
Table 6. Number of sires and percentage average relationship among them (in parentheses; diagonal) for cows born between 2003 and 2006 in the 3 populations, number of common sires (lower triangle), and percentage of average genetic relationships among sires across countries (upper triangle)

\begin{tabular}{lccc}
\hline Country & Great Britain & Italy & Ireland \\
\hline Great Britain & $4,713(4.86)$ & 5.38 & 3.67 \\
Italy & 367 & $4,986(6.54)$ & 4.16 \\
Ireland & 280 & 147 & $1,707(3.01)$ \\
\hline
\end{tabular}

approximately $10 \%$ for the Holstein. The AGREL between GBR and IRL bulls was higher than the AGREL for bulls used within IRL. Thus, GBR and IRL seem to be sampling a greater number of common bulls. The AGREL within ITA was highest, indicating that more related bulls are being used within ITA than within GBR and IRL. Wickham and Banos (1998) observed a general increase in the average relationship among bulls used in Interbull countries from 1970 to 1990.

In conclusion, the average $F$ computed from the joint pedigree was slightly more than $2 \%$ but was 10 to $15 \%$ higher compared with a value averaged from estimates within the individual countries. This was due mostly to a higher degree of completeness of pedigree in the joint pedigree, especially for common sires and dams. The $\mathrm{Ne}$ estimated from the joint pedigree was approximately $12 \%$ lower compared with estimates in each population. There was no marked difference in the average genetic relationship in top cows selected on the basis of PIV compared with milk within GBR and ITA. A lower weight on production, such as in IRL, was more effective in reducing the degree of relatedness among top animals selected on PIV. Selection based on different indexes in each country has resulted in a reduction in relatedness across the 3 countries. The use of common sires accounted for the majority of the relatedness among cows. More common bulls were sampled in GBR and IRL, but more related bulls were used in ITA.

\section{REFERENCES}

Biffani, S., A. B. Samore, and F. Canavesi. 2002. PFT: The new selection index for Italian Holstein. Interbull Bull. 29:142-146.

Fikse, W. F., J. H. Jakobsen, and C. Gustafsson. 2006. Selection of sires in different countries for global dairy breeds. Commun. 0140 in Proc. 8th World Congr. Genet. Appl. Livest. Prod. Belo Horizonte MG, Brazil.

Fikse, W.F., and J. Philipsson. 2007. Development of international genetic evaluations of dairy cattle for sustainable breeding programs. Genet. Resour. Inf. Bull. 41:29-43.

Irish Cattle Breeding Federation. 2008. Annual report for calendar year 2007. http://www.icbf.com/publications/files/Report_May_2008_ ver_7.pdf

Maignel, L., D. Boichard, and E. Verrier. 1996. Genetic variability of French dairy breeds estimated from pedigree information. Interbull Bull. 14:49-54.

Mark, T., W. F. Fikse, H. Jorjani, and J. Philipsson. 2002. Monitoring changes in the structure of global dairy cattle populations. Proc. 7th World Congr. Genet. Appl. Livest. Prod. 33:505-508.

Mrode, R. A., G. T. J. Swanson, and C. M. Lindberg. 1998. Genetic improvement in dairy cattle and its consequence on effective population size. Pages 25-48 in 6th Minist. Agric., For. and Fish. Int. Workshop Genet. Resour., Tsukuba, Japan. Ministry of Agriculture, Forestry and Fisheries, Tokyo, Japan.

Sorensen, A. C., M. K. Sorensen, and P. Berg. 2005. Inbreeding in Danish dairy cattle breeds. J. Dairy Sci. 88:1865-1872.

Stott, A. W., M. P. Coffey, and S. Brotherstone. 2005. Including lameness and mastitis in a profit index for dairy cattle. Anim. Sci. 80:41-52.

Weigel, K., R. Rekaya, F. Fikse, N. Zwald, and D. Gianola. 2000 Data structure and connectedness issues in international dairy sire evaluation. Interbull Bull. 25:26-30.

WickhamB. W.BanosG. 1998. Impact of international evaluations on dairy cattle breeding. Proc. 6th World Congr. Genet. Appl. Livest. Prod. (Armidale, Australia) 23:315-320. 